\title{
Roles of Mast Cells and Histamine in Mosquito Bite-Induced Allergic Itch-Associated Responses in Mice
}

\author{
Eiji Ohtsuka ${ }^{1}$, Sanae Kawai ${ }^{1}$, Tomohiro Ichikawa ${ }^{1}$, Hiroshi Nojima ${ }^{1}, K_{\text {Kanji Kitagawa }}{ }^{1}$, Yoshikazu Shirai ${ }^{2}$, \\ Kiyoshi Kamimura ${ }^{2}$ and Yasushi Kuraishi ${ }^{1, *}$ \\ ${ }^{1}$ Department of Applied Pharmacology, Faculty of Pharmaceutical Sciences \\ and ${ }^{2}$ Department of Biodefense Medicine, Faculty of Medicine,
}

Toyama Medical and Pharmaceutical University, 2630 Sugitani, Toyama 930-0194, Japan

Received October 30, 2000 Accepted February 22, 2001

\begin{abstract}
We investigated itch-associated responses (scratching) to mosquito bites and the role of histamine and mast cells in mosquito-induced itching in mice. Although the first bites of mosquito Aedes albopictus did not increase scratching, repeated bites increased scratching. The response was not diminished even after an interval of 2 months. Similarly, repeated intradermal (i.d.) injections of salivary gland extract (SGE) from Aedes albopictus increased scratching after SGE injection itself and mosquito bites. The scratching peaked within $10 \mathrm{~min}$ and almost subsided by $60 \mathrm{~min}$. The opioid antagonist naloxone $(1 \mathrm{mg} / \mathrm{kg}$, s.c.) inhibited scratching following SGE injection. Although the non-sedative $\mathrm{H}_{1}$-histamine-receptor antagonist terfenadine $(30 \mathrm{mg} / \mathrm{kg}$, p.o.) significantly suppressed scratching induced by histamine $(100 \mathrm{nmol} / \mathrm{site}$, i.d.) in either naive or mosquito-sensitized mice, it did not affect mosquito-induced scratching in mosquitosensitized mice. Repeated injections of SGE increased scratching in mast cell-deficient (WBB6F1-W/W $\mathrm{W}^{v}$ ) mice as well as in normal (WBB6F1-+/+) littermates. Repeated exposure to mosquito bites roughly doubled serum concentrations of total $\mathrm{IgE}$ and $\mathrm{IgG}_{1}$, but not $\mathrm{IgG}_{2 \mathrm{a}}$. Repeated injections of SGE markedly increased plasma extravasation induced by mosquito bites and such an increase was almost completely suppressed by terfenadine $(30 \mathrm{mg} / \mathrm{kg}$, p.o.). The results show the presence of histamine-mediated and histamineindependent mechanisms in cutaneous itching and suggest that histamine probably released from mast cells does not play an important role in itching in immediate allergic reaction. Our murine model of mosquito itching may be useful for studying the mechanisms of immediate allergic itching.
\end{abstract}

Keywords: Immediate allergic itch, Mosquito bite, Itch-associated response, Mast cell, Histamine

Allergic skin disorders, such as atopic dermatitis, contact dermatitis and urticaria, are accompanied by severe pruritus $(1,2)$. The primary target cells in immediate allergic reactions are mast cells, which are main sites of histamine storage and have high affinity immuoglobulin E (IgE) receptors on the plasma membrane. As intradermal (i.d.) injection of histamine elicits itch, this biogenic amine may be involved in allergic itch sensation. However, many inflammatory mediators of mast cells and neuropeptides of primary afferents also elicit itch following i.d. injection in human subjects $(3,4)$. In mice, histamine does not always induce an itch-associated response such as scratching $(5-7)$. Although substance $P$ produces the degranulation of cutaneous mast cells to release histamine $(8,9)$, this degranulation

*Corresponding author. FAX: +81-76-434-5045

E-mail: kuraisiy@ms.toyama-mpu.ac.jp does not play an important role in substance P-induced scratching in mice (10). NC mice show chronic dermatitis, IgE hyperproduction and severe scratching, although they do not show scratching following an i.d. injection of histamine (11), suggesting that histamine is not involved in the chronic pruritus in NC mice. Therefore, the precise mechanisms of chronic allergic pruritus, especially the roles of mast cells and the mediator histamine, are unclear. Thus, we were interested in whether mast cells and histamine would be involved in immediate allergic pruritus.

Some insects are an important source of allergens producing an immediate response in humans. A number of biting insects cause intense allergic reactions. Although the bites of many insects generally elicit pain sensation as well as itch, the bite of mosquitoes causes mainly itch $(12,13)$. Mosquito bites cause immediate and delayed local cutaneous reactions and occasionally systemic reactions $(13-15)$. 
When volunteers are bitten by a mosquito for the first time, there is no immediate cutaneous response or itch (12). However, itch as well as allergic cutaneous reactions develops after repeated mosquito bites (12). The bite of a mosquito whose salivary duct has been cut does not produce wheal and itching (16). The serum concentrations of $\operatorname{IgE}$ and $\operatorname{IgG}$ specific for mosquito salivary gland were higher in subjects with immediate reactions to mosquito bites than in those without immediate reactions (15). Mosquito extract-induced proliferation of lymphocytes was higher in the subjects with delayed reactions than those without delayed reactions (15). Serum from patients with mosquito allergy causes immediate cutaneous reactions in mosquito bite-tolerant subjects (17). These findings taken together suggest that mosquito bite-induced itch is a result of an allergic reaction, probably to antigenic materials in the salivary gland.

Mice that have been exposed repeatedly to mosquito bites develop an immediate wheal after treatment with mosquito antigens, while naive mice do not (18). Repeated i.d. injections of recombinant mosquito salivary allergen increase $\mathrm{IgE}$ and $\mathrm{IgG}_{1}$ and induce immediate skin reaction in mice (19). Thus, mosquito bites and injections of salivary allergen may produce allergic cutaneous reactions in mice. In the present experiments, we first examined whether mosquito bites and injections of extracts of mosquito salivary gland would elicit itch-associated responses in ICR mice which respond to i.d. injection of histamine. Second, we determined the role of mast cells and histamine in itchassociated responses induced by mosquito allergic stimulation.

\section{MATERIALS AND METHODS}

\section{Animals}

Male ICR mice were used, except in one experiment in which genetically mast cell-deficient $\mathrm{WBB} 6 \mathrm{~F} 1-\mathrm{W} / \mathrm{W}^{\mathrm{v}}$ mice and the normal (WBB6F1-+/+) littermates were used, all being from Japan SLC, Inc., Shizuoka. They were 5-weekold at the start of the experiments, except acute experiments in which the mice were used at 5-7 weeks of age. They were housed in a room under controlled temperature (22 $\pm 2{ }^{\circ} \mathrm{C}$ ), humidity $(55 \pm 10 \%)$ and light (light on 07:00 19:00 h). Food and water were freely available. The experimental procedures for mice were conducted in accordance with the guidelines of the Guiding Principles for the Care and Use of Laboratory Animals approved by The Japanese Pharmacological Society.

Mosquitoes Aedes albopictus were bred in our laboratory. They were ordinarily fed on a $3 \%$ sugar solution in a room under controlled temperature $\left(25^{\circ} \mathrm{C}\right)$, humidity (70\%) and light (light on 07:30 - 21:30 h).
Drugs

Histamine (Wako Pure Chemical Ind., Osaka) and naloxone hydrochloride (Sigma Chemical Co., St. Louis, MO, USA) were dissolved in physiological saline. Terfenadine (a generous gift from Dr. M. Satoh, Kyoto University) was suspended in $0.5 \%$ carboxymethyl cellulose. Histamine was injected intradermally into the hair-clipped skin in a volume of $50 \mu \mathrm{l}$. Naloxone hydrochloride $(1 \mathrm{mg} / \mathrm{kg}$ ) was administered subcutaneously $15 \mathrm{~min}$ before the i.d. injection of salivary gland extract in a cross-over fashion; the mice divided into two groups were given either naloxone or saline and switched to the other treatment 7 days later. Terfenadine was administered perorally $30 \mathrm{~min}$ before histamine injection or exposure to mosquito bites. When administered into the mosquito-sensitive mice, terfenadine was administered in a cross-over fashion; the mice divided into two groups were pretreated with terfenadine or the vehicle before mosquito bites and switched to the other treatment 7 days later. One week later, they were pretreated with terfenadine or vehicle before histamine injection and switched to the other treatment 7 days later.

\section{Preparation and injection of extract of mosquito salivary gland}

As female, but not male, mosquitoes suck blood to lay eggs, salivary glands were isolated from female adult mosquitoes. Two hundred mosquitoes were anesthetized by exposure to a cold temperature of $-20^{\circ} \mathrm{C}$, and the thorax including the salivary glands was isolated under a stereoscopic microscope. They were homogenized in a small amount of distilled water at $4^{\circ} \mathrm{C}$, and then the volume was adjusted to $20 \mathrm{ml}$ with distilled water. The suspension was centrifuged at $9,000 \times g$ for $30 \mathrm{~min}$, and then the supernatant was filtered through a cellulose acetate membrane with $0.45-\mu \mathrm{m}$ pores and divided into tubes at a volume of $100 \mu 1$. They were lyophilized and kept at $-80^{\circ} \mathrm{C}$ until use. We designated the dose of sample in a tube as one salivary gland extract (SGE). SGE was injected i.d. in a volume of $50 \mu \mathrm{l}$ twice a week; it was injected generally into the hair-clipped skin of the caudal back and immediately before behavioral observation into the rostral back.

\section{Exposure to mosquito bites}

The hair was clipped from the rostral part of the back the day before the start of the experiment or as needed during the period required for the sensitization to mosquito. The mice were put individually in wire mesh cages $(5 \times 10$ $\times 4 \mathrm{~cm}$ ). Four mice were exposed at a time generally to $50-80$ female mosquitoes that had been fed only on water for $10 \mathrm{~h}$; in one experiment, mice were exposed to $50-80$ male mosquitoes. The 1-h mosquito exposure was ordinarily repeated twice a week for $4-8$ weeks. 


\section{Observation of scratching}

For the observation of scratching after mosquito bites, four mice confined individually in wire mesh cages were put in an acrylic box $(28 \times 32 \times 36 \mathrm{~cm})$ containing $50-80$ female mosquitoes. Immediately after the first mosquito bite of the hair-clipped skin, the murine behaviors were videotaped. For the observation of scratching following the injection of SGE, four mice were put individually into four cells of an acrylic box $(26 \times 18 \times 30 \mathrm{~cm})$ immediately after the extract injection and their behaviors were videotaped. The mice were acclimated to the experimental environment for at least $1 \mathrm{~h}$ just before the experiment and the videotaping of behavior was performed with experimenters kept out of the observation room. Playback served for counting the scratching of the hair-clipped skin by the hind paws as described (10). The mouse generally showed several scratchings for about $1 \mathrm{~s}$ and a series of these movements was counted as one bout of scratching (5).

Determination of serum levels of total $\operatorname{IgE}, \operatorname{Ig} G_{1}$ and $\operatorname{Ig}_{2 a}$ Blood was collected from the abdominal aorta using a $21 \mathrm{G}$ needle under chloral hydrate $(300 \mathrm{mg} / \mathrm{kg})$ anesthesia and centrifuged at $4^{\circ} \mathrm{C}$ at $2,000 \times g$ for $20 \mathrm{~min}$. The supernatant was kept at $-80^{\circ} \mathrm{C}$ until assay. The levels of total $\operatorname{IgE}, \operatorname{IgG}_{1}$ and $\operatorname{IgG}_{2 \mathrm{a}}$ in the serum were determined with the sandwich enzyme immunoassay, as described (11). For the IgE assay, anti-mouse IgE monoclonal antibody (mAb) MCA419 (1/500; Serotec, Oxford, UK), biotin conjugated anti-mouse IgE mAb MCA420B (1/500, Serotec), and anti-DNP IgE mAb SPE-7 (Yamasa Syouyu, Chiba) were used as the first and second antibodies and standard, respectively. For the $\operatorname{IgG}_{1}$ or $\operatorname{IgG}_{2 \mathrm{a}}$ assay, goat $\mathrm{x}$-mouse $\mathrm{IgG}_{1}$ - or $\mathrm{IgG}_{2 \mathrm{a}}$-affinity purified (1/100; Bethyl, Montgomery, TX, USA), goat $\mathrm{x}$-mouse $\mathrm{IgG}_{1}$ - or $\mathrm{IgG}_{2 \mathrm{a}}$-horseradish peroxidase (1/1000, Bethyl) and mouse Ig reference serum (Bethyl) were used as the first and second antibodies and standard, respectively. After treatment with streptavidine-horseradish peroxidase conjugate $(1 / 1000$; Gibco BRL, Gaithersburg, USA) and then $o$-phenylene diamine (Wako Pure Chemical Ind.), the fluorescence at $490 \mathrm{~nm}$ was measured with $365 \mathrm{~nm}$ excitation.

\section{Toluidine blue staining}

A piece of the skin was removed from the rostral back and fixed in $4 \%$ formaldehyde in $0.1 \mathrm{M}$ phosphate buffer (pH 7.3) overnight at a room temperature. After sufficient washing with tap water, the skin was embedded in paraffin by the conventional method, cut into $5-\mu \mathrm{m}$ sections and stained with toluidine blue for the observation of mast cells. Stained cells were counted in an area of $5 \mathrm{~mm}$.

\section{Plasma extravasation}

For the observation of plasma extravasation, $150 \mu 1$ of $1 \%$
Evans blue dissolved in physiological saline was injected into the tail vein of mice. After $10 \mathrm{~min}$, the mice were exposed to female mosquitoes, as described above. They were euthanized via cervical dislocation 20 min after mosquito bites, the skin (hair-clipped region) was removed, and the bluish area of the skin (a circle of 9-mm diameter) was punched out. The amount of Evans blue in the skin was determined by the method of Katayama et al. (20). In brief, the skin sample was incubated in $200 \mu \mathrm{l}$ of $1 \mathrm{~N} \mathrm{KOH}$ overnight at $37^{\circ} \mathrm{C}$. After the addition of $1.8 \mathrm{ml}$ of $0.6 \mathrm{~N}$ $\mathrm{H}_{3} \mathrm{PO}_{4} /$ acetone $(5: 13)$ to the sample solution, insoluble components were removed with filtration through a cotton stopper. The filtrate was centrifuged at $3,000 \times g$ at $4^{\circ} \mathrm{C}$ for $1 \mathrm{~h}$, and the concentration of Evans blue was determined spectrophotometrically at $620 \mathrm{~nm}$.

\section{Statistical analyses}

Values are represented as the mean and S.E.M. Statistical significance was determined with Student's $t$-test, paired $t$-test, one-way analysis of variance (ANOVA) followed by Dunnett's multiple comparisons and repeated measures two-way ANOVA. For all tests, differences were considered significant at $P<0.05$.

\section{RESULTS}

\section{Scratching after mosquito bites}

When the mice were bitten by female mosquitoes for the first time in their life, they showed some scratching behaviors, the frequency of which was similar to that following exposure to male mosquitoes (Fig. 1A). However, when the exposure to female mosquitoes was repeated twice a week, the number of scratch bouts increased gradually depending on the number of times that an animal was exposed to a mosquito bite (Fig. 1A); the number of scratch bouts was significantly $(P<0.05$, Dunnett's test) greater after the fourteenth exposure than after the exposure to male mosquitoes. When the fifteenth exposure was carried out 2 months after the fourteenth exposure, there was no apparent difference in scratching between the fourteenth and fifteenth exposure (Fig. 1A). Figure 1B shows the time-course of scratching following the fourteenth exposure to female mosquitoes; the peak response was during the initial 10 -min period after mosquito bites and the responses almost subsided by $60 \mathrm{~min}$.

\section{Scratching after injection of extract of mosquito salivary glands}

When naive mice were given an i.d. injection of SGE, the number of scratch bouts was not dependent on the concentration $(1 / 1,000-1)$ of SGE and the number of scratch bouts after the injection was not significantly different from that of saline (Fig. 2A). Repeated injections of 

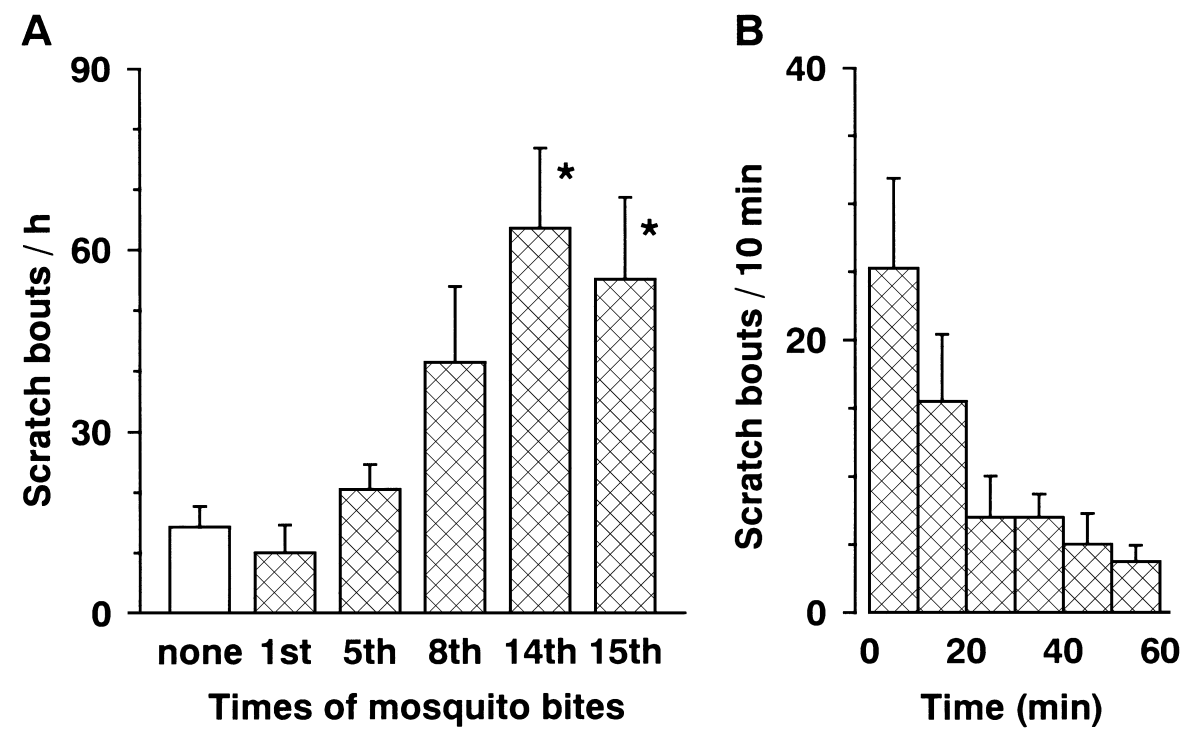

Fig. 1. Scratching responses of ICR mice to repeated exposure to mosquito bites. A) Increase in the frequency of scratching after the repetition of mosquito bites. The mice were exposed to male mosquitoes (none) and then female mosquito bites twice a week until the fourteenth exposure. The fifteenth exposure was performed 2 months after the fourteenth. ${ }^{*} P<0.05$, when compared with the exposure to male mosquitoes (Dunnett's test). B) Time-course of scratching following the fourteenth exposure to mosquito bites. Values represent the means and S.E.M. of $7-8$ animals.

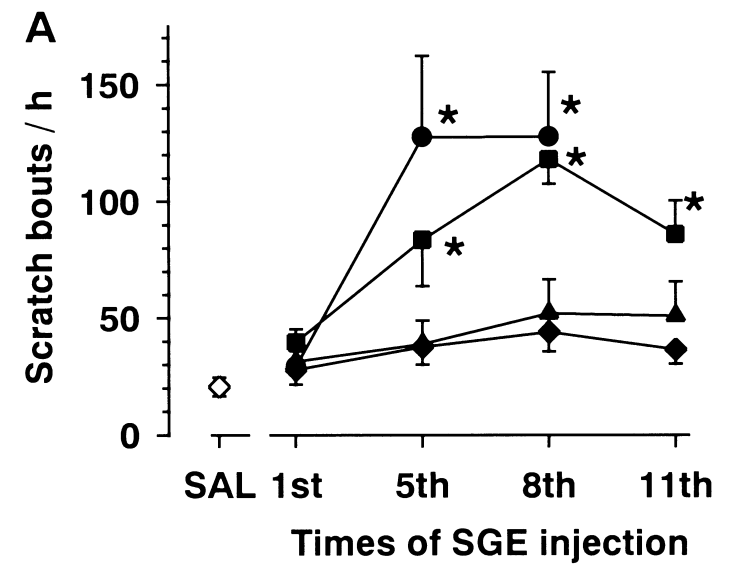

B

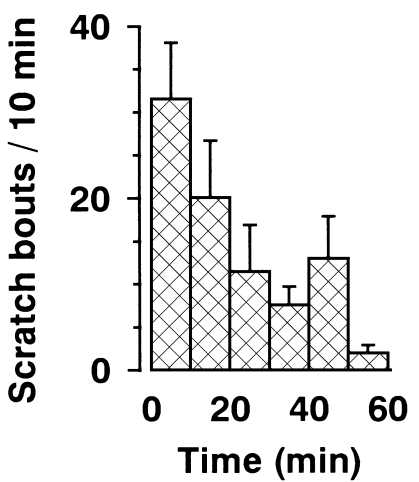

1 and $1 / 10$ SGE, but not $1 / 100$ and 1/1,000 SGE, significantly increased scratching (Fig. 2A). As shown in Fig. 2B, the responses peaked during the initial 10-min period following the eleventh injection of $1 / 10 \mathrm{SGE}$ and almost subsided by $60 \mathrm{~min}$.

To determine whether repeated injections of SGE would affect the scratching responses to mosquito bites, we compared mosquito bite-induced scratching of the mice given repeated injections of SGE with that of naive mice. When the mice were exposed to mosquito bites 45 days after eight injections of SGE, they showed apparent scratching (Fig. 2C). Naloxone (1 mg/kg) partially but significantly $(P<0.05$, repeated measures two-way ANOVA) inhibited SGE-induced scratching (Fig. 3).

Fig. 2. Effects of repeated injections of salivary gland extract (SGE) of mosquitoes on the scratching of ICR mice following SGE injection and mosquito bites. A) The mouse was given an intradermal injection of saline (SAL, open diamond) or SGE at doses of 1/1,000 (closed diamond), 1/100 (closed triangle), 1/10 (closed square) and 1 (closed circle) salivary glands of one mosquito into the rostral back twice a week. ${ }^{*} P<0.05$, as compared with saline (Dunnett's test). B) Time-course of scratching following the eleventh injection of $1 / 10$ SGE. C) Scratching responses after mosquito bite. The treated mice were exposed to mosquito bites 45 days after 8 times of injections of SGE from one mosquito twice a week and naive mice were exposed to mosquito bites without injection of SGE. ${ }^{*} P<0.05$, (Student's $t$-test). Values represent the means and S.E.M. of 8 animals. 


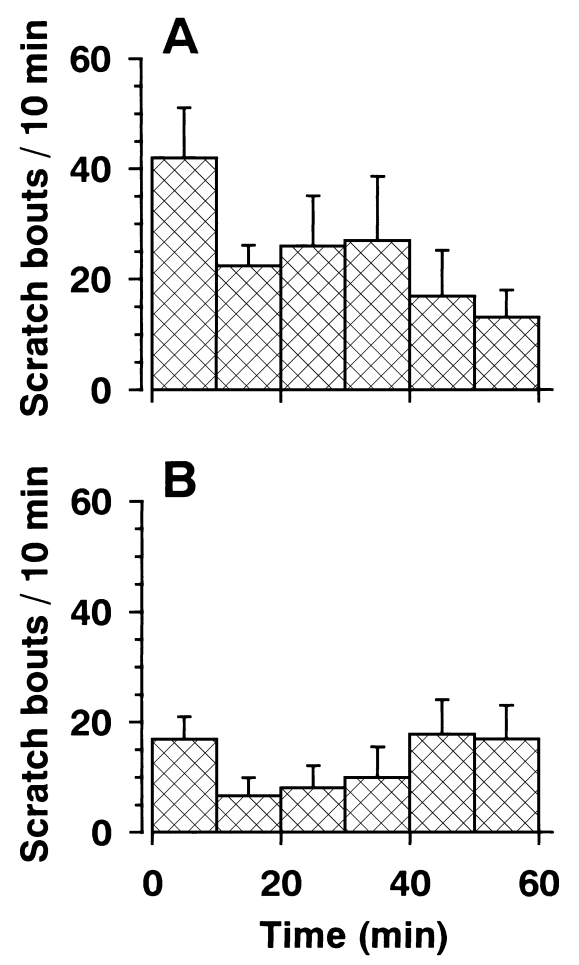

Fig. 3. Effect of naloxone on scratching induced by an intradermal injection of salivary gland extract in ICR mice. The mice were given 8 injections of 1 SGE (extract from salivary glands of one mosquito) for 2 months. Thereafter, they were given 2 injections of $1 / 10 \mathrm{SGE}$ and the scratching was counted for one hour after each injection. Saline (A) and naloxone ( $1 \mathrm{mg} / \mathrm{kg}$; B) were administered subcutaneously $15 \mathrm{~min}$ before the SGE injection in a cross-over fashion. Values represent the means and S.E.M. of 8 animals. Repeated measures two-way analysis of variance: main effect of naloxone, $F(1,7)=6.59$, $P<0.05$.

\section{Roles of histamine and mast cells in scratching}

An i.d. injection of histamine (1, 10 and $100 \mathrm{nmol} / \mathrm{site})$ dose-dependently increased scratching in healthy mice (Fig. 4A). Peroral pretreatment with terfenadine (3, 10 and $30 \mathrm{mg} / \mathrm{kg}$ ), a non-sedative $\mathrm{H}_{1}$ histamine receptor antagonist, dose-dependently inhibited scratching induced by histamine $(100 \mathrm{nmol} / \mathrm{site}$, i.d.), with a significant inhibition at a dose of $30 \mathrm{mg} / \mathrm{kg}$ (Fig. 4B). Therefore, in the following experiments, we administered terfenadine at a dose of $30 \mathrm{mg} / \mathrm{kg}$. In mice that had been exposed repeatedly to mosquito bites, an i.d. injection of histamine $(100 \mathrm{nmol}$ /site) elicited apparent scratching and the histamine effect was significantly $(P<0.05$, paired $t$-test $)$ suppressed by pretreatment with terfenadine at a dose of $30 \mathrm{mg} / \mathrm{kg}$ (Fig. 4C). In contrast, the same dose of terfenadine did not affect the scratching following mosquito bites (Fig. 4C).

In mast cell-deficient (WBB6F1-W/Wv) mice, the first i.d. injection of 1/10 SGE did not increase scratching, as compared with saline (Fig. 5A). Although the fifth injection of SGE did not yet increase scratching, the eighth

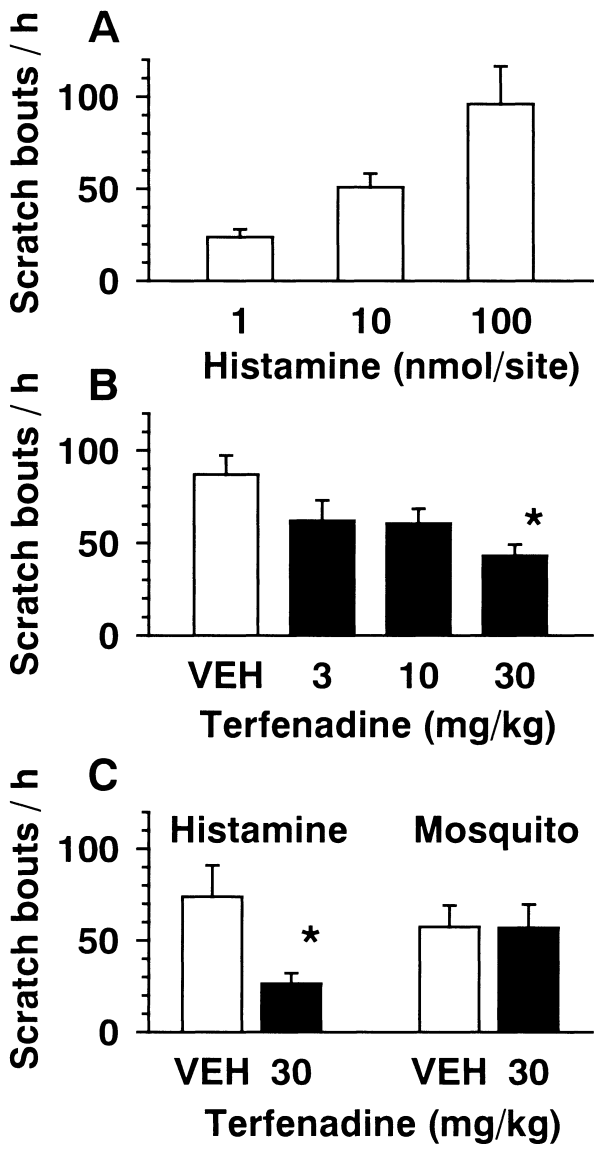

Fig. 4. Effects of terfenadine on scratching induced by an intradermal injection of histamine and mosquito bite in ICR mice. A) Histamine-induced scratching in naive ICR mice. B) Effects of terfenadine on the histamine-induced scratching in naive ICR mice. Terfenadine or vehicle was administered perorally $30 \mathrm{~min}$ before histamine $(100 \mathrm{nmol} / \mathrm{site})$ injection. $* P<0.05$, when compared with vehicle (Dunnett's test). C) Effects of terfenadine on histamine- and mosquito bite-induced scratching in mosquito-sensitized mice. The mice were exposed to mosquito bites 15 times for 2 months. Thereafter, terfenadine $(30 \mathrm{mg} / \mathrm{kg})$ was administered perorally $30 \mathrm{~min}$ before histamine injection or mosquito bite. ${ }^{*} P<0.05$ (Student's $t$-test). Values represent the means and S.E.M. of 8 animals.

and eleventh SGE injections significantly increased the response. There were no apparent differences in the effects of repeated injections of SGE and in the time-course after the eleventh injection between the mast cell-deficient and control mice (Fig. 5). The number of toluidine blue-stained cells in the skin was $24.4 \pm 5.3(\mathrm{n}=7)$ and $1.6 \pm 0.7$ cells $15 \mathrm{~mm}(\mathrm{n}=7)$ in WBB6F1-+/+ and WBB6F $1-\mathrm{W} / \mathrm{W}^{\mathrm{v}}$ mice, respectively.

\section{Serum concentrations of total $\operatorname{IgE}, \operatorname{Ig} G_{1}$ and $\operatorname{Ig} G_{2 a}$}

The serum concentrations of total $\mathrm{IgE}$ and $\mathrm{IgG}_{1}$ in mice that had been exposed repeatedly to mosquito bites and showed apparent scratch responses was about twice those of naive mice, although only the difference in $\mathrm{IgG}_{1}$ was 

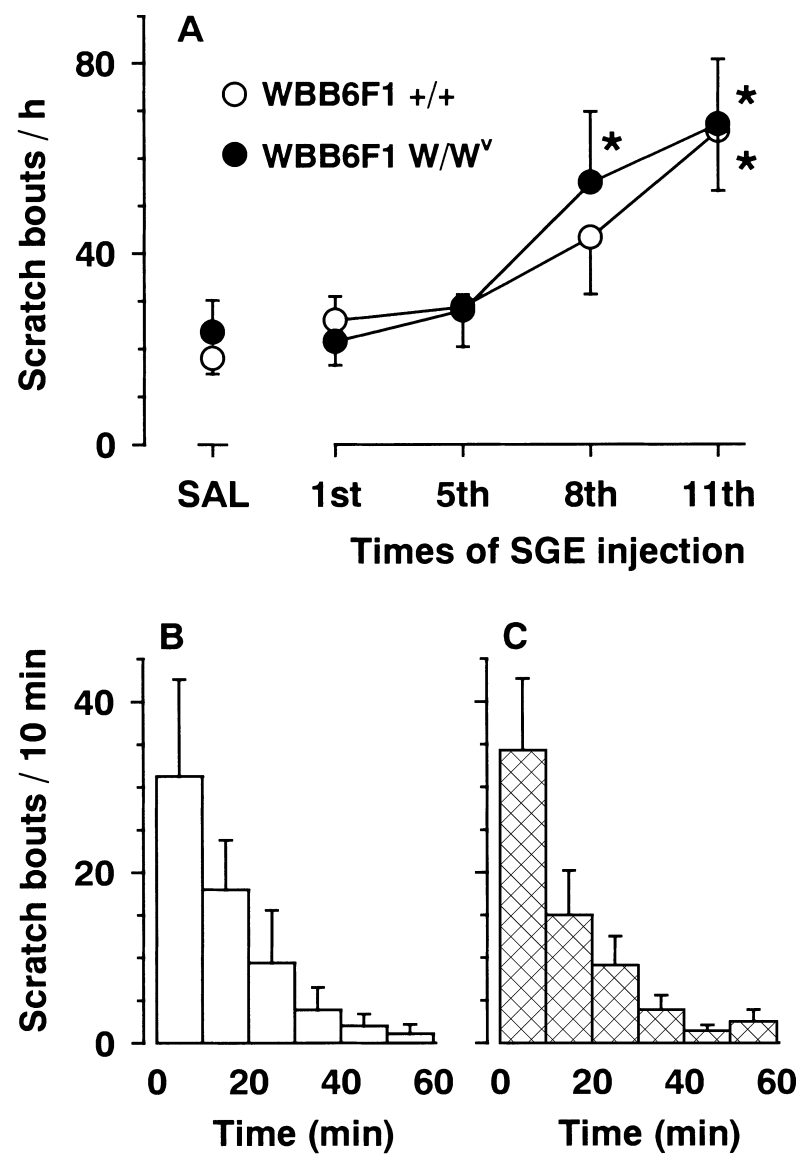

significant (Fig. 6). On the other hand, the serum concentration of $\operatorname{IgG}_{2 \mathrm{a}}$ was not altered after repeated mosquito bites (Fig. 6).

\section{Plasma extravasation after mosquito bites}

Figure 7 shows typical examples of plasma extravasation after mosquito bites. When the naive mice were exposed to mosquito bites, there were scattered blue spots in the skin (Fig. 7A). On the other hand, mosquito bites in the mice that had been given repeated injections of SGE produced a marked increase in plasma extravasation (Fig. 7B). This increase was obviously inhibited by peroral pretreatment with terfenadine at a dose of $30 \mathrm{mg} / \mathrm{kg}$ (Fig. 7C). The amount of extravasated dye was $2.7 \pm 0.5,6.1 \pm 1.4$ and $2.2 \pm 0.6 \mu \mathrm{g} / \mathrm{ml}(\mathrm{n}=8$ each group) in naive, SGE-sensitized and SGE-sensitized plus terfenadine-treated groups, respectively; significant effects, $F(2,21)=6.20, P<0.01$, were revealed with one-way ANOVA.

Fig. 5. Scratching responses to repeated injections of salivary gland extract (SGE) in mast cell-deficient mice (WBB6F1-W/Wv) and normal littermates (WBB6F1-+/+). A) Effects of repeated injections of SGE on scratch response. The mice were given an intradermal injection of saline (SAL) and from 3 days later, 1/10 SGE twice a week. ${ }^{*} P<0.05$, when compared with SAL (Dunnett's test). $B, C)$ The time-course of scratching following eleventh injection of $\mathrm{SGE}$ in $\mathrm{WBB} 6 \mathrm{~F} 1-+/+(\mathrm{B})$ and $\mathrm{WBB} 6 \mathrm{~F} 1-\mathrm{W} / \mathrm{W}^{\mathrm{v}}$ mice $(\mathrm{C})$. Values represent the means and S.E.M. of $7-8$ animals.
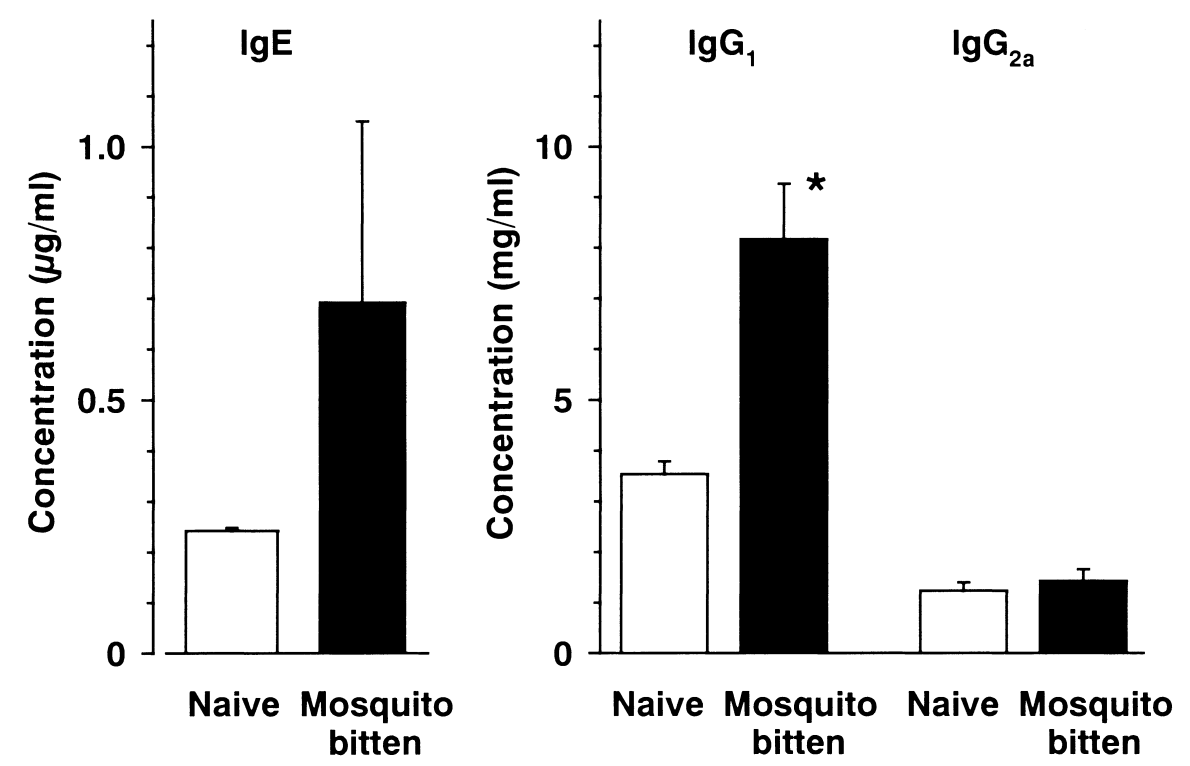

Fig. 6. Effects of repeated mosquito bites on the serum concentrations of total $\operatorname{IgE}, \operatorname{IgG}_{1}$ and $\operatorname{IgG}_{2 a}$ in $I C R$ mice. Part of the mice shown in Fig. 1A were further exposed to mosquito bites at 2 months and then the blood was used for assays. Naive mice were age-matched and not exposed to mosquito bites. $\mathrm{n}=5-6 .{ }^{*} P<0.05$ (Student's $t$-test). 

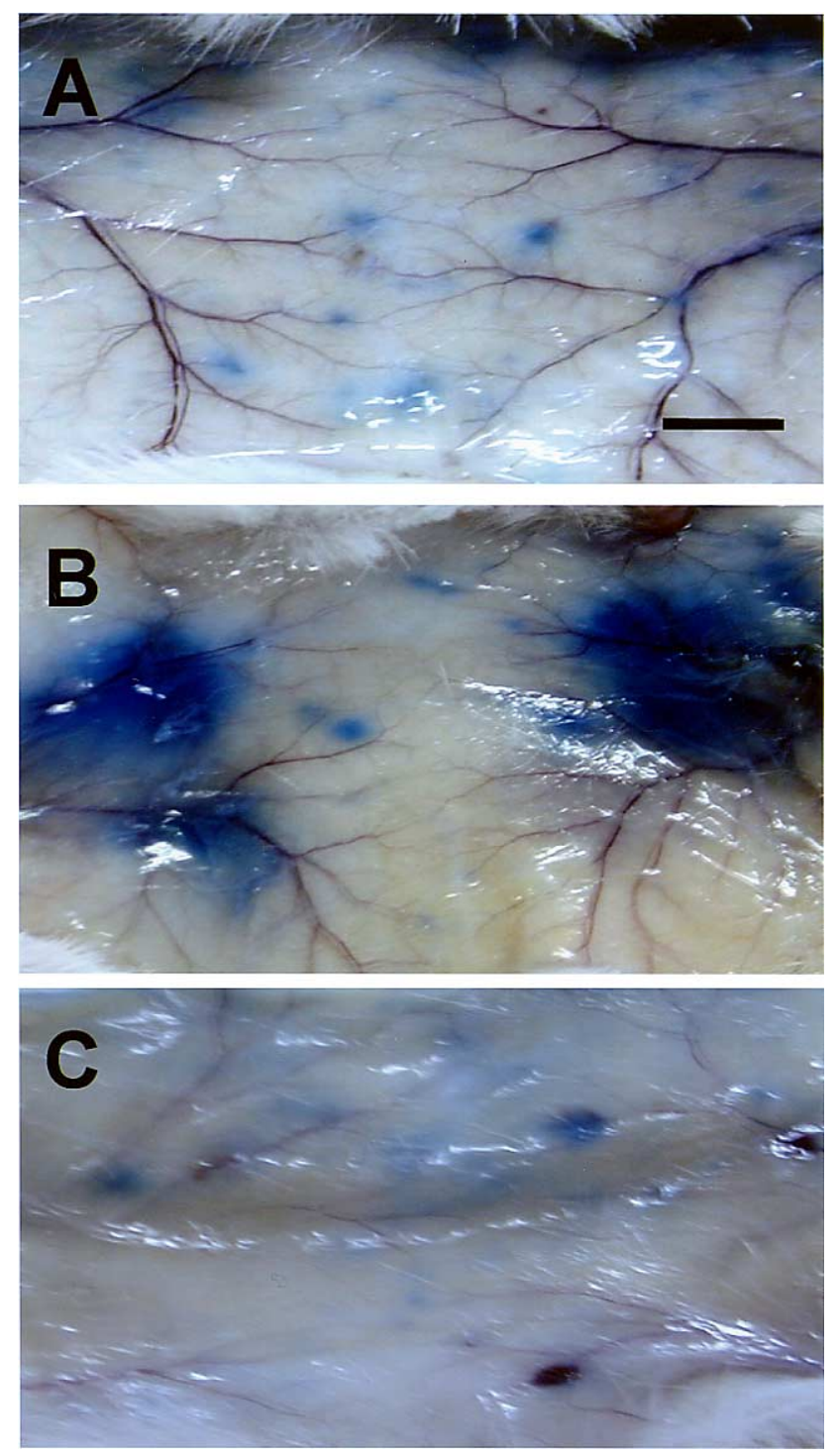

Fig. 7. Plasma extravasation after mosquito bites. Mosquito bitesinduced plasma extravasation in naive (A), SGE-sensitized (B) and terfenadine-treated SGE-sensitized mice (C). Terfenadine $(30 \mathrm{mg} / \mathrm{kg})$ was perorally administered $30 \mathrm{~min}$ before exposure to mosquito bites. Scale bar $=5 \mathrm{~mm}$.

\section{DISCUSSION}

There are histamine, polyamines, esterases and peptides in the salivary gland of the mosquito (21). However, as the first mosquito bites (and the first injection of extract of salivary gland) did not increase scratching in mice, these substances in saliva may not be pruritogenic. Repetition of mosquito bites and SGE injection increased scratching and the increased response to the bite was sustained at an interval of 2 months. In addition, mosquito bites elicited apparent scratching in mice that had been given repeated injections of SGE. The results are consistent with mosquito bite-induced pruritus in humans $(13,22)$ and suggest that scratching was due to the sensitization to antigen(s) in saliva. The scratching after mosquito bites and SGE injection was relatively fast in onset and almost subsided by $60 \mathrm{~min}$. Therefore, this response may be due to the immediate allergic reaction. In human subjects, mosquito bites induce delayed reactions as well as immediate reactions $(13,15)$. A delayed papule was also reported in mice (18). Whether mosquito bites elicit delayed type of itching in mice is an interesting question to be clarified in a future study.

The serum concentrations of total $\mathrm{IgE}$ and $\mathrm{IgG}_{1}$, but not $\mathrm{IgG}_{2 \mathrm{a}}$, in mice exposed repeatedly to mosquito bites were about twice those of naive mice. The results are consistent with another report in which serum concentrations of total $\mathrm{IgE}$ and mosquito antigen-specific $\mathrm{IgG}_{1}$, but not $\mathrm{IgG}_{2 \mathrm{a}}$, were increased in mosquito-sensitized mice (18). In addition, repeated injections of SGE markedly increased plasma extravasation after mosquito bites. These results support the idea that the scratching is due to an immediate allergic reaction.

Repeated injections of $1 / 10$ SGE significantly increased scratching, while those of 1/100 SGE produced a slight, but not significant, increase. The number of scratch bouts after repeated mosquito bites was a little more than that of $1 / 100$ SGE injections. The eighth injection of $1 / 100$ SGE did not significantly elicit scratching, while mosquito bites after 8 injections of $1 / 10$ SGE induced significant and remarkable scratching. Thus, the host might be given saliva antigen in an amount corresponding to $1 / 100-1 / 10 \mathrm{SGE}$ during the feeding of mosquito.

The scratching following SGE injection was suppressed by the opioid antagonist naloxone. Similarly, the opioid antagonist inhibits pruritogen-induced scratching $(6,10)$ and spontaneous scratching in mice with chronic dermatitis (11). The opioid antagonists also inhibit itching and scratching in patients with pruritic diseases $(23-25)$ and histamine-induced itch in normal volunteers (26). With these findings taken into account, the present result suggests that the scratching after SGE injection (and probably mosquito bites) was an itch-associated response. I.d. injections of various opioids do not increase scratching in mice (27). On the other hand, intracisternal and intrathecal injections of morphine and $\mu$-opioid receptor agonists elicit scratching, which is suppressed by naloxone $(27-29)$. Therefore, the primary site of inhibitory action of opioid antagonist on itch-associated scratching may be the central, rather than the peripheral, nervous system. With regard to human subjects, itch is the common side effect of epidural and intrathecal injections of morphine (for review, see ref. 30), and itch induced by epidural morphine is inhibited by naloxone and opioid receptor antagonist $(31,32)$. Thus, it is possible that opioid antagonists act on the central nervous system to inhibit itching in human subjects and itch-associated 
response in mice.

The $\mathrm{H}_{1}$ histamine receptor antagonists cetirizine and ebastine inhibit mosquito bite-induced pruritus in human subjects $(13,33)$. Based on these findings, it is suggested that histamine plays an important role in mosquito-induced itching. However, contrary to expectations, mosquito-induced itch-associated responses of the mice were not affected by the $\mathrm{H}_{1}$-histamine-receptor antagonist terfenadine at a dose that inhibited histamine-induced itch-associated responses. Thus, the results strongly suggest that histamine does not play a primary role in mosquito-induced itching in mice and raise the possibility of the involvement of itch mediator(s) other than histamine. An increase in plasma extravasation after mosquito bites under sensitized conditions was almost completely inhibited by terfenadine, suggesting that mosquito bites released histamine probably from mast cells. Although the cutaneous concentration of histamine after mosquito bites is unclear, it might not be enough to induce itching in mice. Although our results do not deny the role of histamine in mosquito-induced itching in humans, it is possible that mediator(s) other than histamine are also involved in mosquito-induced itching in human subjects.

In mosquito-sensitized mice, mosquito antigens elicit an immediate wheal reaction (18). In addition, the number of mast cells is lower in the skin of mosquito-bitten ears than in the skin of unbitten ears (34). Thus, mast cells are certainly involved in allergic cutaneous reactions in mosquito-sensitized mice. However, itch-associated responses following SGE injection were not apparently different between mast cell-deficient and normal control mice, suggesting that there are mast cell-independent mechanisms in allergic itching. At present, we do not know the mechanisms of mosquito bite-induced itching. One possible explanation is that in sensitized conditions, allergic reaction released itch mediator(s) from intradermal cells other than mast cells. We can not deny the possibility that the sensitivity of itch-signaling neurons was increased by repetition of mosquito bites or SGE injection. However, the number of scratch bouts elicited by an i.d. injection of histamine was not significantly different between naive and sensitized mice. Therefore, change in neuronal sensitivity may not play a critical role in mosquito bite-induced itching in mice.

In summary, we showed for the first time that mosquito bite elicits scratching in mice. This scratching may be due to itch associated with the immediate allergic reaction to mosquito saliva. Mast cells and histamine may not play important roles in this response. This mouse model of mosquito itching may be useful for investigating the mechanisms, especially a mast cell-independent system, of immediate allergic itching.
Acknowledgments

We wish to express out thanks to Dr. J.G. Collins of the Yale University School of Medicine for helpful discussion and suggestion. This work was partly supported by Grants-in-Aid for Scientific Research (B) (10470509) and for Exploratory Research (11877382) from the Ministry of Education, Science, Sports and Culture of Japan.

\section{REFERENCES}

1 Lorette G and Vaillant L: Pruritus: current concepts in pathogenesis and treatment. Drugs 39, 218 - 223 (1990)

2 Klecz RJ and Schwartz RA: Pruritus. Am Family Physician 45, 2681 - 2686 (1992)

3 Hägermark Ö: Itch mediators. Seminars Dermatol 14, 271 - 276 (1995)

4 Greaves MW and Wall PD: Pathophysiology of itching. Lancet 348, 938 - 940 (1996)

5 Kuraishi Y, Nagasawa T, Hayashi K and Satoh M: Scratching behavior induced by pruritogenic but not algesiogenic agents in mice. Eur J Pharmacol 275, 229 - 233 (1995)

6 Yamaguchi T, Nagasawa T, Satoh M and Kuraishi Y: Itchassociated response induced by intradermal serotonin through 5- $\mathrm{HT}_{2}$ receptors in mice. Neurosci Res 35, 77 - 83 (1999)

7 Kitagawa K, Andoh T, Nagasawa T, Satoh M and Kuraishi Y: Different effects of antagonists to histamine and serotonin receptors on itch-related behavior induced by substance $\mathrm{P}$, histamine and serotonin in mice. Jpn J Pharmacol 73, Suppl I, 93P (1997)

8 Benyon RC, Lowman MA and Church MK: Human skin mast cells: their dispersion, purification, and secretory characterization. J Immunol 138, 861 - 867 (1987)

9 Ebertz JM, Hirshman CA, Kettelkamp NS, Uno H and Hanifin JM: Substance P-induced histamine release in human cutaneous mast cells. J Invest Dermatol 88, 682 - 685 (1987)

10 Andoh T, Nagasawa T, Satoh M and Kuraishi Y: Substance P induction of itch-associated response mediated by cutaneous NK1 tachykinin receptors in mice. J Pharmacol Exp Ther 286, 1140 - 1145 (1998)

11 Yamaguchi T, Maekawa T, Nishikawa Y, Nojima H, Kaneko M, Kawakita T, Miyamoto T and Kuraishi Y: Characterization of itch-associated responses of NC mice with mite-induced chronic dermatitis. J Dermatol Sci 25, 20 - 28 (2001)

12 Mellanby K: Man's reaction to mosquito bites. Nature 19, 554 (1946)

13 Reunala T, Lappalainen P, Brummer-Korvenkontio H, Coulie P and Palosuo T: Cutaneous reactivity to mosquito bites: effect of cetirizine and development of anti-mosquito antibodies. Clin Exp Allergy 21, 617 - 622 (1991)

14 McCormack DR, Salata KF, Hershey JN, Carpenter GB and Engler RJ: Mosquito bite anaphylaxis: immunotherapy with whole body extracts. Ann Allergy Asthma Immunol 74, 39 - 44 (1995)

15 Peng $Z$, Yang $M$ and Simons FER: Immunologic mechanisms in mosquito allergy: correlation of skin reactions with specific $\mathrm{IgE}$ and $\mathrm{IgG}$ antibodies and lymphocyte proliferation response to mosquito antigens. Ann Allergy Asthma Immunol 77, $238-$ 244 (1996)

16 Hudson A, Bowman L and Orr CMW: Effect of absence of saliva on blood feeding by mosquitoes. Science 131, $1730-$ 1731 (1960) 
17 Reunala T, Brummer-Korvenkontio H, Rasanen L, Francois G and Palosuo T: Passive transfer of cutaneous mosquito-bite hypersensitivity by IgE anti-saliva antibodies. J Allergy Clin Immunol 94, 902 - 906 (1994)

18 Chen YL, Simons FER and Peng Z: A mouse model of mosquito allergy for study of antigen-specific $\operatorname{IgE}$ and $\operatorname{IgG}$ subclass response, lymphocyte proliferation, and IL-4 and IFN- $\gamma$ production. Int Arch Allergy Immunol 116, 269 - 277 (1998)

19 Wang H, Mao X, Simons FE and Peng Z: Induction of IgE responses using a recombinant mosquito salivary allergen $\mathrm{rAed}$ a 2 without adjuvant in mice. Int Arch Allergy Immunol 120, 135 - 140 (1999)

20 Katayama S, Shionoya $\mathrm{H}$ and Ohtake S: A new method for extraction of extravasated dye in the skin and the influence of fasting stress on passive cutaneous anaphylaxis in guinea pigs and rats. Microbiol Immunol 22, 89 - 101 (1978)

21 Nakayama Y, Kawamoto F, Suto C, Nakajima T, Yasuhara T, Fujioka $\mathrm{H}$ and Kumada N: Histamine and esterases in the salivary gland of the mosquito, Culex pipiens pallens. Jpn J Sanit Zool 36, 315 - 326 (1985)

22 Karppinen A, Rantala I, Vaalasti A, Palosuo T and Reunala T: Effect of cetirizine on the inflammatory cells in mosquito bites. Clin Exp Allergy 26, 703 - 709 (1996)

23 Summerfield JA: Naloxone modulates the perception of itch in man. Br J Clin Pharmacol 10, 180 - 183 (1980)

24 Monroe EW: Efficacy and safety of nalmefene in patients with severe pruritus caused by chronic urticaria and atopic dermatitis. J Am Acad Dermatol 21, 135 - 136 (1989)

25 Bergasa NV, Talbot TL, Alling DW, Schmitt JM, Walker EC,
Baker BL, Korenman JC, Park Y, Hoofnagle JH and Jones EA: A controlled trial of naloxone infusions for the pruritus of chronic cholestasis. Gastroenterology 102, 544 - 549 (1992)

26 Bernstein JE, Swift RM, Soltani K and Lorincz AL: Antipruritic effect of an opiate antagonist, naloxone hydrochloride. J Invest Dermatol 78, 82 - 83 (1982)

27 Kuraishi Y, Yamaguchi $\mathrm{T}$ and Miyamoto T: Itch-scratch responses induced by opioids through central mu opioid receptors in mice. J Biomed Sci 7, 248 - 252 (2000)

28 Tohda $\mathrm{C}$, Yamaguchi $\mathrm{T}$ and Kuraishi Y: Intracisternal injection of opioids induced itch-associated response through $\mu$-opioid receptors in mice. Jpn J Pharmacol 74, 77 - 82 (1997)

29 Yamaguchi T, Kitagawa K and Kuraishi Y: Itch-associated response and antinociception induced by intracisternal endomorphins in mice. Jpn J Pharmacol 78, 337 - 343 (1998)

30 Ballantyne JC, Loach $\mathrm{AB}$ and Carr DB: Itching after epidural and spinal opiates. Pain 33, $149-160$ (1988)

31 Penning JP, Samson B and Baxter AD: Reversal of epidural morphine-induced respiratory depression and pruritus with nalbuphine. Can J Anaesth 35, 599 - 604 (1988)

32 Saiah M, Borgeat A, Wilder-Smith OHG, Rifat K and Suter PM: Epidural-morphine-induced pruritus: propofol versus naloxone. Anesth Analg 78, 1110 - 1113 (1994)

33 Reunala T, Brummer-Korvenkontio H, Petman L, Palosuo T and Sarna S: Effect of ebastine on mosquito bites. Acta Derm Venereol 77, 315 - 316 (1997)

34 Wilson $\mathrm{AB}$ and Clements $\mathrm{AN}$ : The nature of the skin reaction to mosquito bites in laboratory animals. Int Arch Allergy 26, $294-314(1965)$ 